\title{
Decomposition Analysis of Health Inequality among Rural Households in Nigeria
}

\author{
Awoniyi Olabisi Alaba (Corresponding author) \\ Department of Agricultural Economics and Extension Bowen University, Iwo, Osun State Nigeria \\ Tel: 234-803-407-6556_E-mail: bisiexcel@yahoo.com
}

Adeoti Adetola I.

Department of Agricultural Economics, University of Ibadan, Ibadan, Oyo State, Nigeria

Tel: 234-805-055-884Ｅ-mail: jadeoti@yahoo.com

Falusi Abiodun

Department of Agricultural Economics, University of Ibadan

Ibadan, Oyo State, Nigeria

Tel: 234-801-8452-7520Ｅ-mail: afalusi@yahoo.com

Received: March 21, 2011

Accepted: April 8, $2011 \quad$ Online Published: December 1, 2011

doi: $10.5539 /$ jas.v4n1p239

URL: http://dx.doi.org/10.5539/jas.v4n1p239

\begin{abstract}
This study profiled and decomposed health inequality among rural households in Nigeria. Core Welfare Indicator Questionnaire data obtained by National Bureau of Statistics in 2006 was used. The data set comprised of 59,567 rural households. Data were analyzed using generalized entropy and Shapley decomposition.

Level of disparity in access to health care service is 0.320 . North East and South West Zone have the highest (0.333) and least incidence of health inequality (0.286). Furthermore, more than $80 \%$ of health inequality is as a result of dynamics within various socio-economic groups.

The study therefore concludes that health inequality exists in Nigeria especially in the North and there is the need for increased commitment by all stakeholders in order for the country to be able to achieve the millennium development goals on health issues which are to reduce child mortality, improve maternal health and combat AIDS, malaria and other diseases
\end{abstract}

Keywords: Generalized entropy, Health, Inequality and shapley decomposition

\section{Introduction}

Inequality as been defined as not only referring to differences in income or consumption expenditure between population groups that hinder the welfare of these groups, but also to discrepancies in social and political indicators (Justino et al 2003). Inequality has been relatively neglected in the past few decades compared with poverty and growth. However, recent empirical work, which has brought it back on the development agenda tend to focus primarily on inequality in incomes or consumption levels. One of the several dimensions of inequality that has been relatively neglected is inequality in health (Omilola 2004).

International Organizations such as the World Health Organization and United Nations Development Program have viewed health as the most important goal for human development and the fundamental indicator of social development (Feng and Yangyang 2006). Health is not only instrumental in enabling people to earn a living, and to enjoy the fruits of their labors, but is an important element of well-being in it own right, in fact, the health status of a nation is an important indicator of well-being of its citizenry (Iyun 1988). An effort to improve health in developing countries faces many challenges. This further includes high incidence of infectious and communicable diseases, growing burdens of chronic and non-communicable diseases, weak health systems, and 
inadequate human and material resources. Investment in health care service delivery is expected to bring about improvement in such key health sector indicators as geographical access to health care service facilities by the populace would improve the utilization rate of these facilities as well as impact positively, by way of reducing the burden of household expenditure on health care delivery.

Improving access and quality to general health care is an important component of economic growth and poverty reduction because it shapes human capital and livelihood opportunities. Health disparities are therefore a major public health and social justice concern as even in the most affluent of countries, less well off members of populations suffer from a disproportionate amount of morbidity, and live shorter lives than those who are better off (Pradhan et al 2003 Frohlich et al. 2006). This study therefore sets out to answer the following pertinent questions: What is the level of access to health care delivery? To what extent is the level of disparity in access to health care service delivery among households in rural Nigeria and finally what is the marginal contribution of within and between health inequalities to the total health inequality among rural households in the country?

Provisions of answers to the questions raised will generate some policy issues and give directions to policymakers within the framework of identifying the socio-economic groups that have unequal access to health care. This will provide empirical basis for identifying the most vulnerable socio-demographic groups for policy targeting.

\section{Literature Review}

Srinivasan (2000) recognized that poverty and inequality are multifaceted phenomenon that goes beyond inadequate income and was reflected in the prevailing low life expectancy, high rates of infant, child, and maternal mortality and general morbidity. Contrary to the numerous studies (Aigbokhan (2000), Olaniyan and Awoyemi 2006, Oyekale 2009) on poverty, equity and redistribution of existing wealth one scarcely finds studies that analyse equitable distribution of opportunities such as health among others that equally constitutes a precondition for individual's productivity and ability to move beyond the poverty line. This is caused by the common misconception in the literature that income inequality is closely related to other forms of inequality and can thus be used as a proxy for the level and changes in overall inequality in any given society. But it has been recognized (Sahn and Younger 2007; Haddad et al. 2003; Appleton and Song 1999) that there is a low correlation between income and many other measures of living standards, particularly health. Health status is correlated with income, both for individuals within nations, and across nations in aggregate and there is a widespread evidence that health system performance in low and middle income countries is inequitable but the correlation is far from perfect so that looking at health leads to different assessments of well-being than come from looking only at income. Therefore, just as measuring the dispersion of income is of interest, so too are statements about inequality in health status (Pradhan et al 2003).

Gakidou et al (2000) "define health inequality to be the variations in health status across individuals in a population. Thus, one of the most widely-cited definitions of health inequity is that it "refers to differences in health which are considered unfair and unjust. Health disparities are a major public health and social justice concern as even in the most affluent of countries, less well off members of populations suffer from a disproportionate amount of morbidity, and live shorter lives, than those who are better off Frohlich et al. 2006

\section{Research Methodology}

\subsection{Study Area}

Nigeria is located in the Sub-Sahara African nations and situated in the western part of Africa on the Gulf of Guinea and lies between $4^{\circ} 161$ and $13^{\circ} 531$ north latitude and between $2^{\circ} 40^{\prime}$ and $14^{\circ} 41^{\prime}$ east longitude. It occupies a total land area of 910,800 square kilometres (World Bank Atlas 2001). The population is still predominantly rural, accounting for approximately $53 \%$ of the population dwellers and majority of them are into agriculture. The National Population Commission put the population of Nigeria at about 140 million (NPC 2006) with population growth declining to 3.2 percent (FRN, 2007).

\subsection{Sampling Technique and Sampling Size}

The study used Core Welfare Indicator Questionnaire Survey data set obtained by the National Bureau of Statistics. A two- stage cluster sample design was adopted in selecting respondents from each of the Local Government Areas (LGA). The first stage was the demarcation of the Enumeration Areas (EAs), while the selection of the Housing Units (HUs) constituted the second stage. In each LGA, a systematic selection of 10 EAs was made and $10 \mathrm{HUs}$ were selected from each EA. Overall, 77,400 households were drawn of which 59,567 were rural which served as the sample size for the study.

The data that were extracted from the COWIQ data set includes the following; socio-demographic characteristics 
(gender, age of household head, household size, marital status, geo-graphical location), type of health care service providers consulted, problems encountered during consultation, distance to the nearest health care centre, house ownership and housing conditions (floor materials, wall materials, roofing materials), household sanitation among others.

\subsection{Analytical Techniques}

In order quantify and present health inequality profile for households in rural Nigeria, Gini index was implored. The Shapley decomposition technique was used to estimate the contribution of within and between group inequality to total inequality and the ordered probit regression technique would be used to identify the factors that determine the level of access to health care service delivery in rural Nigeria.

\subsubsection{Generalized Entropy (GE)}

The GE was used to measure inequality in access to health care service delivery because it allows the examination of the stability of the welfare rankings for different weightings (Justino 2004). The value of GE ranges from 0 to 1 , with zero representing equal distribution and higher values represent higher levels of inequality.

Members of the GE class of measures have the general formula as follows. The General equation for the generalized entropy is given as follows

$$
\mathrm{GE}_{(\alpha)}=\frac{1}{\alpha-\alpha^{2}}\left[\frac{1}{n} \sum_{i=1}^{n}\left(\frac{y}{y}\right)^{\alpha}-1\right]
$$

Following Litchfield 1999 the GE for health inequality is given below.

GE $(0)=$ Mean log deviation

$$
\frac{1}{n} \sum_{i=1}^{n} \log \frac{y_{i}}{\bar{Y}}
$$

GE (1) $=$ Theil Entropy index

$$
\frac{1}{n} \sum_{i=1}^{n} \frac{y_{i}}{\bar{Y}} \log \frac{y_{i}}{\bar{Y}}
$$

GE (2) $=$ Coefficient of variation

$$
C V=\frac{1}{Y}\left[\frac{1}{n} \sum_{i=1}^{n}\left(y_{i}-\bar{Y}\right)^{2}\right]^{\frac{1}{2}}
$$

Where $\mathrm{n}$ is the population, $\mu_{h}$ is the mean level of access to health care service delivery. $\mathrm{H}_{\mathrm{i}}$ is the level of access to health care service delivery by household, and $i_{h}$ is the corresponding rank of access to health care service delivery. The level of household's access to health care service was derived by computing an index through the use of Principal Component Analysis (PCA). The PCA creates uncorrelated indices or components, where each component is a linear weighted combination of the initial variables.Mathematically, it is expressed as

$$
\mathrm{PC}_{1}=\mathrm{a}_{11} \mathrm{X}_{1}+\mathrm{a}_{12} \mathrm{X}_{2}+{ }_{-}+\mathrm{a}_{1 \mathrm{n}} \mathrm{X}_{\mathrm{n}}
$$

Where $a_{11}$ to $a_{1 n}$ represents the weight for the first principal component and the nth variable. The weights are given by the eigen vectors of the correlation matrix

The indicators of the access to health care service delivery and the weights attached to these indicators/components are given below

Type of health care service delivery consulted

( 4 = Government, 3 = Private, $2=$ Traditional, $1=$ Self medication, $0=$ none $)$

Distance to the nearest Health care service delivery centre

(4= less than $15 \mathrm{mins}, 3=15-29 \mathrm{mins}, 2=30-44 \mathrm{mins}, 1=45 \mathrm{mins}-1 \mathrm{hr}$ )

Problems encountered at the time of visit

$4=$ No problem, $3=$ Long waiting hours and facilities not clean, $2=$ No drugs, $1=$ Too expensive, $0=$ No trained professionals/ treatment unsuccessful, 
Reason for not consulting medical service delivery

$4=$ No need, $3=$ Too expensive, $2=$ others, $1=$ Too far

\subsubsection{Shapley Decomposition}

In order to decompose and estimate the contribution of within and between health inequalities to the total health inequality, the Shapley decomposition model was used. The study followed Duclos and Araar, (2006). Precisely, let an inequality index $I$ depend on the level of access to health care service delivery, in $k=1, \ldots, K$ groups, each group with $n(k)$ individuals. Let $\mathrm{h}(\mathrm{k})$ be the $\mathrm{n}(k)$-vector of level of access to health care delivery of group $k$. The total inequality $I$ is expressed as a sum of between- and within- group inequality

$$
\mathrm{I}\left(\mathrm{h}(1), \ldots ., \mathrm{h}(\mathrm{K})=\mathrm{I}_{\text {between }}+\mathrm{I}_{\text {within }}\right.
$$

To compute the contribution of between-group inequality, the fall of inequality observed is computed when the level of access to health care delivery of the groups are equalized. Hence,

$\mathrm{I}_{\text {between }}$ for health inequality $=$

$$
0.5(h(1), \ldots, h(K))-I(\mu / \mu(1) \cdot h(1, \ldots, \mu / \mu(k) . h(K))+I(\mu(1) .1(1), . . \mu(K) .1(K))-0\}
$$

Where $1(k)$ is a unit vector of size $n_{k}$. The within-group contribution is then given as

I within for health inequality $=$

$$
0.5(h(1), \ldots, h(K))-I(\mu / \mu(1) . h(1, \ldots, \mu / \mu(k) . h(K))+I(\mu(1) .1(1), . . \mu(K) .1(K))-0\}
$$

The second step consists of decomposing total within-group inequality as a sum of within-group inequality across groups.

\section{Result and Discussion}

\subsection{State of Access to Health Care services}

The distribution of level of access to health care service delivery among households in the rural areas of the country is presented in table 1 . The result implies that access to health care services is generally low in the rural areas of the country. The reason for this is because of the poor state of infrastructural development in the rural areas of the country coupled with the fact that most of their roads are not quite accessible which discourages most of the medical personnel posted to the rural areas not to stay. This therefore has led to the slow development of medical services in the rural areas of the country.

In addition, the result indicated the North West Zone has the Zone with the highest percentage of households with low level of access to health care service delivery while households in the South West Zone have the highest percentage of households with high level of access to health care service delivery. The reason for the low level of access to health care service is because of the high incidence of poverty in this Zone since most of the poorest states belong to this Zone. This therefore implies that there is the need for more investment in the health sector of the country especially in the northern region and most especially in the North West Zone of the country where level of access to health care service delivery is poor through the provision of drugs, medical personnel's and establishment of more medical centres.

\subsection{Health Inequality Profile among Rural Households in Nigeria}

Table 2 presents the result of the inequality profile for the level of access to health care service delivery among households in rural Nigeria. The result reveals that the health inequality index across the mean of the population $\left(\mathrm{GE}_{1}\right)$ is 0.320 with the North East and South West Zone having the highest and least health inequality with indices of 0.342 and 0.286 respectively. While inequality among households with low (lower tail) access to health care centre for rural households is 0.192. It is also highest and least in the North East and South West Zone with indices of 0.181 and 0.222 respectively. The result further indicated that health inequality among households with high access (upper tail) to health care service delivery is 0.336 . In addition health inequality is also highest in the North East zone and least in the South West with indices of 0.457 and 0.309 .

The result of health inequality indicates that health inequality is prevalent in the Northern region of country. This might be due to the fact that households in the North have the highest incidence of poverty (NBS 2004) since most of the poorest states are in this region. This is likely to have negative effect on the amount that they can spend on accessing health care service delivery centres. This is in line with the study of Ityavyar 1998 on Health services inequalities in Nigeria. The outcome revealed that Geographical inequities have been the result of uneven development due to the concentration of missionaries in Southern Nigeria for about $1 / 2$ century before extending to the North. 


\subsection{Shapley Health Inequality Decomposition}

The result of the total health inequality decomposition into within and between group marginal contributions is presented in table 3 . The result shows that health inequality is as a result of disparity within the various socioeconomic characteristics rather than dynamics between the groups. For decompositions with respect to gender, within health inequality accounts for $97.6 \%$ of total health inequality for households in the rural areas of the country with the male headed households contributing $78.3 \%$ of the total health inequality.

The result of the Shapley health inequality decomposition by household size for rural households in Nigeria indicates that $98.2 \%$ of total dynamics in access to health care service delivery can be attributed to difference within household size compositions of the rural households and rural households that consist of 6 to 10 members contributes $53.8 \%$ of the total health inequality while rural households with more than ten members contribute the least percentage $4 \%$ of the total dynamics in access to health care service delivery.

The result of Shapley health inequality decomposition by age reveals that dynamics in access to health care service delivery is more within the age groups and it accounts for $96.8 \%$ of the total health inequality. Rural household head's that are between 31 and 60 years contributes $60.5 \%$ of the total health inequality. Rural households whose household heads are not older than 31 years contribute the least percentage $(8.6 \%)$ to the total dynamics in access to health care service delivery.

The result of Shapley health inequality decomposition into within and between contribution by marital status shows that polygamous homes in the rural areas of the country contributes $49.9 \%$ of the total health inequality. Households whose household heads are single contributes the least percentage of $0.7 \%$ to the total health inequality.

The decomposition of health inequality into within and between marginal contributions by geo-political zones indicates that dynamics within the zones contributes more $(82.7 \%)$ to the disparity in access to health care services. The result of the intra-group decomposition indicates that the North East Zone contributes the highest percentage $(27.8 \%)$ to health inequality while the South West Zone contributes the least percentage $(5 \%)$ to the total health inequality.

The result of the Shapley health inequality conforms to the outcome of Baye 2005 that also indicated that inequality is attributed to differences within groups than dynamics between groups and that inequality within groups is the most important aspect of inequality (Baye 2005)

\section{Summary, Conclusion and Recommendation}

This study analyzed the level of disparity in access to health care service delivery and its determinant among households in rural Nigeria. The national data on Core Welfare Indicator Questionnaire Survey for the country which was conducted by the NBS in 2006 was used. The whole national data obtained was stratified into rural and urban households and the whole data for rural households in Nigeria which comprised of 59,567 households served as the sample size were analyzed and interpreted. The data were analyzed using descriptive statistics, generalized entropy and Shapley decomposition techniques.

The result revealed that the level of disparity in access to health care service delivery among households in the rural areas of the country is 0.335 with the zones in the Northern region of the country having higher incidence of inequality in access to health care service delivery than households in the Southern region. The result of the Shapley decomposition shows that inequality is more as a result of differences within the various socio-economic groups rather than dynamics between the various socio-economic groups.

The study therefore concludes that inequality in access to health care service delivery calls for attention and there is the need for government, private, non-governmental organizations and other stake holders that are involved in the health sector to increase their commitment to the health sector and most especially in the Northern regions of the country where the level of health inequality is high. This is pertinent in order for the country to be able to achieve the millennium development goal on health issues which are to reduce child mortality, improve maternal health care among others.

\section{References}

Appleton, S., \& L. Song. (1999). Income and Human Development at the Household Level: Evidence from Six Countries. Oxford: Centre for the Study of African Economies, Oxford University. Mimeo.

Baye F.M. (2008). Exact Configuration of Poverty, Inequality and Polarization Trends in the Distribution of Well-being in Cameroon Paper Presented at the Centre for the Study of African Economies (CSAE) Conference 2008 on "Economic Development in Africa", St Catherine's College, Oxford, 16-18 March, 2008. 
Duclos Jean-Yves \& A. Araar. (2006). Poverty and Equity: Measurement, Policy and Estimation with DAD. Springer and the International Development Research Centre (IDRC).

Frohlich K. L., Ross N, Richmond C. (2006). Health disparities in Canada today: Some evidence and a theoretical framework www. Sciencedirect.com

Gakidou, E. E., Murray, C. J. L. and Frenk, J. (2000). Defining and Measuring Health Inequality: An Approach Based on the Distribution of Health Expectancy. Bulletin of the World Health Organisation, 78 (1): 42-54.

Haddad, L., H. Alderman, A. Appleton, L. Song, \& Y. Yohannes. (2003). Reducing Child Malnutrition: How Far Does Income Growth Take Us? World Bank Economic Review, 17 (1):107-31. http://dx.doi.org/10.1093/wber/lhg012

Justino, P. (2003). Measuring Non-Income Inequalities. PRUS Working Paper no. 15.

Litchfield, J. (2001). Poverty, Inequality and Social Welfare in Brazil 1981-1995. PhD Thesis, London School of Economic, University of London, London: Routledge.

NPC. (2006). National Population Commission 2006 Census Report.

Olaniyan O \& Awoyemi T.T. (2006). Inequality in the Distribution of Household Expenditure in Rural Nigeria: A decomposition analysis. A Research Report Submitted to the African Economic Research Consortium (AERC), Nairobi for the Second Phase Collaborative Poverty Research Project.

Oyekale A.S., Adeoti A.I \& Oyekale T.O. (2006). Measurement and sources of inequality in Rural and Urban Nigeria. A final report submitted to Poverty and Economic Policy Network, Canada

Omilola, B. (2004). Decomposing Inequalities in Nutritional Status of Children in Kenya. Paper presented at the International Conference-.Promoting Human Rights and Social Policies for Children and Women: Monitoring and Achieving the Millennium Development Goals., organized by the United Nation's Children's Fund and the Graduate Program in International Affairs at the New School University in New York City between April 28-30, 2004.

Pradhan M, Sahn D.E., Younger S.D. (2003). Decomposing world health inequality. Journal of Health Economics, 22 (2003) 271-293 University of Sussex, Brighton. http://dx.doi.org/10.1016/S0167-6296(02)00123-6

World Bank Atlas. (2001). The World Bank Atlas Pp 36-37.

Sahn and Younger. (2007). Inequality and Poverty in Africa in an Era of Globalization Looking Beyond Income to Health and Education. UNU/WIDER research paper No 2007/74.

Table 1. State of Access to Health Care Service Delivery

\begin{tabular}{|l|l|l|l|}
\hline Geo-political zones & $\mathbf{0}-\mathbf{0 . 3 3}($ Low) & $\mathbf{0 . 3 4}-\mathbf{0 . 6 7}$ (Average) & $>\mathbf{0 . 6 7}$ (High) \\
\hline North West & 90.1 & 8.8 & 1.9 \\
North Central & 72.2 & 20.1 & 6.3 \\
North East & 85.8 & 12.3 & 2.7 \\
South East & 60.1 & 34.6 & 5.5 \\
South West & 49.1 & 41.4 & 9.5 \\
South South & 55.0 & 5.4 & 9.4 \\
\hline Total & 68.7 & 25.4 & 5.9 \\
\hline
\end{tabular}

Source: Author's computation from the 2006 COWIQ data 
Table 2: Health Inequality Profile for Rural Households in Nigeria

\begin{tabular}{|l|c|c|c|}
\hline Geo-political Zones & $G e_{0}$ & $G e_{1}$ & $G e_{2}$ \\
\hline North West & 0.2070 & 0.3325 & 0.4393 \\
North Central & 0.1921 & 0.3224 & 0.3989 \\
North East & 0.2215 & 0.3417 & 0.4566 \\
South East & 0.1914 & 0.2986 & 0.3319 \\
South West & 0.1810 & 0.2863 & 0.3091 \\
South South & 0.1898 & 0.2895 & 0.3221 \\
\hline Total & 0.1971 & 0.3202 & 0.3363 \\
\hline
\end{tabular}

Source: Author's computation from the 2006 COWIQ data

Table 3. Shapley Health Inequality Decomposition

\begin{tabular}{|c|c|c|c|c|}
\hline $\begin{array}{l}\text { Socio-economic } \\
\text { variables }\end{array}$ & Gini & Between & Within & Intra group Decomposition \\
\hline Gender & 0.3632 & $0.0086(2.4)$ & $0.3546(97.6)$ & Male: 0.2845 (78.3) Female: $0.0701(19.3)$ \\
\hline Household size & 0.3586 & $0.0063(1.8)$ & $0.3523(98.2)$ & $<6: 0.1451(40.5)$ 6-10: $0.1930(53.8) \quad>10: 0.0142(4.0)$ \\
\hline Age & 0.3656 & $0.0115(3.2)$ & $0.3541(96.8)$ & <30: $0.0315(8.6)$ 31-60: $0.2212(60.5) \quad>$ 60: $0.1013(27.7)$ \\
\hline Marital status & 0.3606 & $0.0288(8.0)$ & $0.3318(92.0)$ & $\begin{array}{llllll}\text { Single: } & 0.0027 & (0.7) & \text { Monogamous: } & 0.0595 & (16.5) \\
\text { Polygamous: } 0.1800 & (49.9) & \text { Informal: } & 0.0071 & (2.0) \\
\text { Divorced: } 0.0825 & (22.9) & & & & \end{array}$ \\
\hline Location & 0.3666 & $0.0633(17.3)$ & $0.3033(82.7)$ & $\begin{array}{l}\text { North West: } 0.0649(17.7) \text { North East: } 0.1018(27.8) \\
\text { North Central: } 0.0563(15.4) \text { South East } 0.0395(10.8) \\
\text { South West } 0.0183(5) \text { South South } 0.0214(6.1)\end{array}$ \\
\hline
\end{tabular}

